\title{
Carotid Cistern
}

National Cancer Institute

\section{Source}

National Cancer Institute. Carotid Cistern. NCI Thesaurus. Code C32263.

The cavity surrounding the internal carotid artery on either side of the optic chiasm. 